\title{
Heterogeneous Fenton Catalyst for the Efficient Removal of Azo Dyes in Water
}

\author{
Miren Blanco, Amaia Martinez, Arrate Marcaide, Estíbaliz Aranzabe, Ana Aranzabe \\ Chemistry of the Surface Unit, IK4-TEKNIKER, Eibar, Gipuzkoa, Spain \\ Email: miren.blanco@tekniker.es
}

Received 23 April 2014; revised 26 May 2014; accepted 3 June 2014

Copyright (C) 2014 by authors and Scientific Research Publishing Inc.

This work is licensed under the Creative Commons Attribution International License (CC BY). http://creativecommons.org/licenses/by/4.0/

(c) (†) Open Access

\begin{abstract}
Heterogeneous Fenton/photo Fenton type processes using a Fe-exchanged zeolite of Y-type have been applied for the degradation of a model textile synthetic water based on Black B azodye. Research work has been directed to compare process efficiency and to establish their advantages over corresponding homogenous Fenton type processes. By optimizing the amount of reactants and process conditions, a complete decolorization of the effluent and a reduction greater than 80 per cent in the total organic carbon content is achieved. The influence of solar radiation on the heterogeneous process has been also studied. Homogeneous and heterogeneous Fenton processes yielded similar decolorization and mineralization, but the concentration of Fe ions in the bulk after the treatment was not significant in the latter case. Moreover, the catalyst support can be reused in successive cycles without significant loss of effectiveness. The use of solar radiation as a source of energy for operating the process accelerates the decomposition of azodye, making the process economical and environmentally sustainable.
\end{abstract}

\section{Keywords}

Zeolite, Heterogeneous Fenton Catalyst, Wastewater Treatment, Dyes

\section{Introduction}

In recent years, the Advanced Oxidation Processes (AOPs) are being widely studied because of their efficiency in removing non-biodegradable industrial wastewater. Among the available AOPs, the Fenton/photo Fenton type are considered the most promising because of its high efficiency, low cost and ease application and because they do not require sophisticated equipment or reagents for being applied [1]-[25]. Basic treatment takes place in homogeneous phase at acidic $\mathrm{pH}$ and with the addition of hydrogen peroxide $\left(\mathrm{H}_{2} \mathrm{O}_{2}\right)$ and $\mathrm{Fe}^{2+}$ salt (catalyst acting), both in darkness (Fenton) or in the presence of light (photo Fenton). OH radicals produced during the reaction 
are highly oxidative and non-selective; therefore they are able to decompose a variety of organic compounds. The main reactions involved are Equations (1)-(4):

$$
\mathrm{Fe}(\mathrm{II})+\mathrm{H}_{2} \mathrm{O}_{2} \rightarrow \mathrm{Fe}(\mathrm{III})+\mathrm{HO}^{\cdot}+\mathrm{HO}^{-}
$$

The ferric ion formed can be reduced by reaction with $\mathrm{H}_{2} \mathrm{O}_{2}$ and generate the ferrous ion with hydroxyl radicals. The overall mechanism has a catalytic character. For this, it is necessary that $\mathrm{H}_{2} \mathrm{O}_{2}$ was in excess of the amount of iron added.

$$
\begin{gathered}
\mathrm{Fe}(\mathrm{III})+\mathrm{H}_{2} \mathrm{O}_{2} \rightarrow \mathrm{HO}^{\circ 2}+\mathrm{Fe}(\mathrm{II})+\mathrm{H}^{+} \\
\mathrm{Fe}(\mathrm{III})+\mathrm{HO}^{\cdot 2} \rightarrow \mathrm{Fe}^{2+}+\mathrm{O}_{2}+\mathrm{H}^{+}
\end{gathered}
$$

When the reaction is conducted in the presence of light, light accelerates the reaction increasing the rate of degradation of contaminants as an extra dose of $\mathrm{HO}^{*}$ are generated. The reaction scheme is shown below.

$$
\mathrm{FeOH}^{2+} \rightarrow v h \rightarrow \mathrm{Fe}^{2+}+\mathrm{HO}^{?}
$$

The process can be conducted both homogeneously [1]-[5] and heterogeneously [6]-[25]. Despite its proven efficiency, advanced oxidation processes have some disadvantages, such as production of sludge with a high content in iron and iron deactivation by the formation of complexing agents.

To solve these problems associated with the implementation of the process in homogeneous phase, recent investigations are focusing on the possibility of using supports for iron ions. For these purposes, various supports such as nafion [6], zeolite [7]-[11], silica [12], clay [13], resins, and activated carbon [14] [15] have been used to prepare novel heterogeneous Fenton catalysts. In heterogeneous phase, the physical steps in addition to chemical changes take place on the surface of the catalyst at the active sites where mass transfer limited adsorption of reactant molecules occurs. At the end of the reaction, the product molecules are desorbed and leave the active sites available for a new set of reactant molecules to attach to the surface and react. These complex steps make the surface characteristics and the pore structure of the solid catalyst become important since these will strongly affect their kinetic rate, efficiency and stability towards solid catalyzed Fenton reaction. The use of iron in heterogeneous phase gives an easy separation of the catalyst and allows its reuse, whereby the overall cost of the process could be greatly diminished.

When considering heterogeneous solid phase, their density, porevolume, pore size distribution, porosity and surface area become crucial factors that need to be taken into consideration. Zeolites are crystalline aluminosilicate materials with a three dimensional framework and four-connected framework structure built from tetrahedra. It is consist of robust, crystalline silica $\left(\mathrm{SiO}_{2}\right)$ and neutral frameworks. At some places in the framework $\mathrm{Al}^{3+}$ replaced $\mathrm{Si}^{4+}$ and the framework carries a negative charge. This $\mathrm{Si} / \mathrm{Al}$ ratiocontrols total acidity as well as acid site strength. Loosely held cations that sit within the cavities preserve the electron eutrality of the zeolite. Those cations are amenable to cation exchange capacities up to several milliequivalents per kilogram and are able to reversibly interact with polar molecules [26]-[28].

Somemajor organic pollutants are derived from synthetic dyes. Synthetic dyes are extensively produced in the $21^{\text {st }}$ century owing to their unique properties such as high wet fastness profile, brilliant shades, and relative low cost and simple synthesis methods. These characteristics have successfully made dying industries such as textile, leather, painting and printing to choose as priority good colorants in their products. Synthetic dyes are normally resistant to mild degradation, as their molecular structure contains complex aromatic amide groups with alkyl, halogen, nitro, hydroxyl, sulfonic acid, substituent(s), and inorganic sodium salts. Over $12 \%$ - 15\% of the overall synthetic dyes production is lost as dye effluent during these wet processing activities. Based on the worldwide demand, it is estimated that over 100,000 commercial dyes are in existence and more than $7 \times 10^{5}$ tonnes are produced annually [15]-[17].

In this paper, the Fenton and photo Fenton processes are applied in heterogeneous phase for the treatment of a synthetic textile water based on Black B azo dye. The effect of solar radiation as a source of energy is analyzed by using lamps which have their maximum emission in the region of $360 \mathrm{~nm}$. The iron required for the development of the Fenton/photofenton process has been supported on a Y-type zeolite through an ion exchange process. We have shown the effectiveness of the developed catalyst in discoloration and decrease of total organic carbon (TOC). Quantification of iron in solution ensures that the iron is not leached from the support and that the oxidation process occurs heterogeneously. Process conditions are optimized by varying the concentration of 
catalyst and $\mathrm{H}_{2} \mathrm{O}_{2}$ content in order to minimize the quantity of reagents and thus the cost of the process. Furthermore, the possibility of reusing the catalyst without significant loss of its effectiveness is shown. The results obtained in heterogeneous elimination processes regarding TOC and color are compared to those in homogeneous phase.

\section{Experimental Part}

\subsection{Materials and Reagents}

The azo dye used in this study was Remazol Black B supplied by DyStar, whose chemical structure is: $\mathrm{C}_{26} \mathrm{H}_{25} \mathrm{~N}_{5} \mathrm{O}_{19} \mathrm{~S}_{6} \mathrm{Na}_{4}$. The initial solution was prepared by adding $0.25 \mathrm{~g}$ of Black $\mathrm{B}$ in $250 \mathrm{ml}$ of distillated water $\left(1.00 \times 10^{-3} \mathrm{M}\right) . \mathrm{H}_{2} \mathrm{O}_{2}(30 \% \mathrm{v})$ is provided by Foret and for adjusting $\mathrm{pH}$ is used $98 \% \mathrm{H}_{2} \mathrm{SO}_{4}$ and $1 \mathrm{M} \mathrm{NaOH}$, both of Scharlab. All solutions were prepared with distilled water, Millipore Mili-RiOs.

The zeolite used is of type Y, CBV 400 Zeolyst International. This has been previously washed with distilled water to remove any impurities, and dried at room temperature. For the ion exchange process ferrous sulfate heptahydrate $\mathrm{FeSO}_{4} \cdot 7 \mathrm{H}_{2} \mathrm{O}(\mathrm{Fe}(\mathrm{II}))$ is used from Sigma Aldrich.

\subsection{Preparation of Heterogeneous Fenton Catalyst}

For the preparation of the Fenton catalyst, $40 \mathrm{~g}$ of dried zeolite is added to $200 \mathrm{ml}$ of a $0.176 \mathrm{M}$ solution of $\mathrm{FeSO}_{4} \cdot 7 \mathrm{H}_{2} \mathrm{O}$ and maintained at reflux at $60^{\circ} \mathrm{C}$ with constant stirring for 6 hours. Subsequently, the zeolite was filtered, washed several times with distilled water to remove the iron which has not been exchanged and dried overnight in an oven at $100^{\circ} \mathrm{C}$. The amount of iron -exchanged in the zeolite is of $43.45 \mathrm{mg} \mathrm{Fe} / \mathrm{g}$ zeolite.

The determination of iron in solution for the quantification of iron exchanged into the zeolite and of possible leaching during the process is performed according to the ISO 6332 standard, applicable for sewage.

\subsection{Experimental Procedures and Analysis}

For performing heterogeneous assays, different concentrations of exchanged zeolite were added into $100 \mathrm{ml}$ of $1.00 \times 10^{-3} \mathrm{M}$ of Black B solutions. The $\mathrm{pH}$ of the solutions was changed to 2.7 by adding $98 \% \mathrm{H}_{2} \mathrm{SO}_{4}$ or $1 \mathrm{M}$ $\mathrm{NaOH}$. Then, the appropriate concentrations of $\mathrm{H}_{2} \mathrm{O}_{2}$ are added while the mixing was provided by a magnetic stirring bar, thus initiating the process. Tests were carried out in darkness, Fenton, and under UV light photo Fenton. For photo Fenton trials have used two UV lamps with an emission maximum at $360 \mathrm{~nm}$, unless specifically specified. All assays were performed at room temperature. Times used for testing $12 \mathrm{~h}$ for photoFenton and for Fenton tests. Samples were taken periodically from the vessel, filtered with a $0.22 \mu \mathrm{m}$ of pore size Teflon filter in order to remove solid particles (when required) and thereafter immediately analyzed.

Decolorization degree was established by measuring the absorbance in visible spectra at characteristic wavelength of used dye $\left(\lambda_{\max }=590 \mathrm{~nm}\right)$ by UV/VIS spectrophotometer, Jasco. The mineralization of the solution was established on the basis of total organic carbon content measurements (TOC), performed by Total Organic Carbon analyzer; Elementar.

Concentrations of iron ions in the bulk were monitored by colorimetric methods using the same UV/VIS spectrophotometer mentioned above. Ferrous ions were identified by the reaction of $\mathrm{Fe}^{2+}$ with 1,10 -phenanthroline, while ferric ions were determined by the reaction of $\mathrm{Fe}^{3+}$ with thiocyanate. Initial and final $\mathrm{pH}$ values were measured using GLP $22 \mathrm{pH}-\mathrm{meter}$, from Crison.

\section{Results and Discussion}

Before applying Fe-exchanged zeolite of Y-type as a catalyst in heterogeneous Fenton process, the set of preliminary experiments was performed in order to investigate its adsorption ability toward Black B dye, including the entire $\mathrm{pH}$ range studied later in theapplication of heterogeneous Fenton type processes. The aqueous dye solutions with addition of adequate amounts of unmodified zeolite and Fe-exchanged zeolite were stirred in the dark for $8 \mathrm{~h}$ and no changes in UV/VIS spectra were recorded, indicating no adsorption of dye onto the zeolites. In addition, the aqueous dye solution with addition of adequate amounts of $\mathrm{H}_{2} \mathrm{O}_{2}$ was stirred in the dark for $8 \mathrm{~h}$ and no changes in UV/VIS spectra were recorded. An image of the final appearance of the solutions after dark stirring at $\mathrm{pH}=2.7$ for $12 \mathrm{~h}$ is shown in the inlet photograph of Figure 1. It can be concluded that in these expe- 


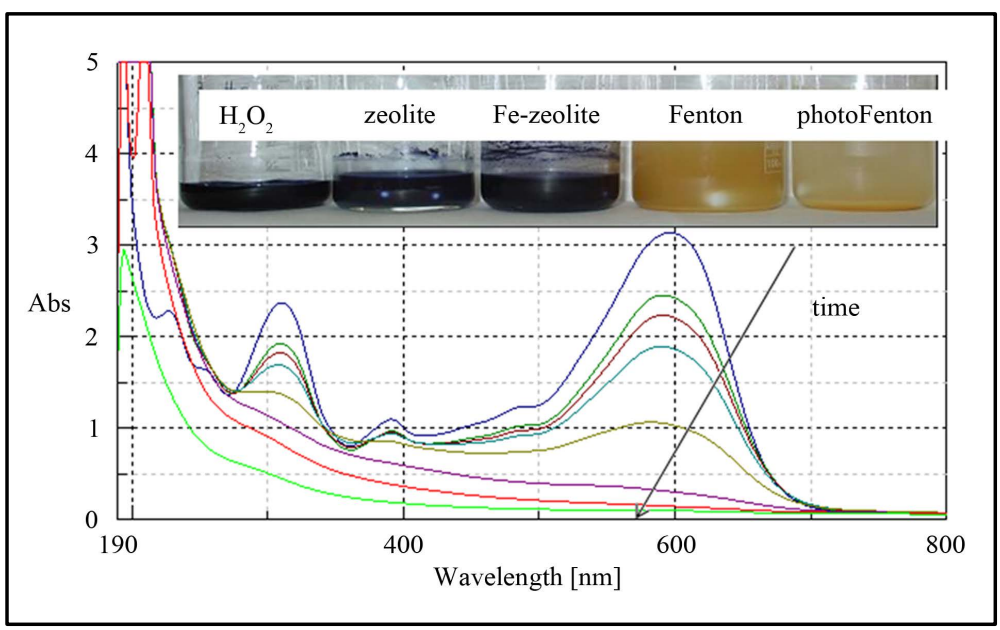

Figure 1. Evolution of the UV-vis absorption spectra of the solution during the process (from blue spectra, $t=0$, to green spectra, $t=8 \mathrm{~h}$ ). Inlet: Photograph of the solutions after being stirred in the dark for $8 \mathrm{~h}$.

riments the adsorption of dye molecule does not contribute to the overall decolorization and mineralization extents.

When applying Fe-exchanged zeolite of Y-type as a catalyst in heterogeneous Fenton process, the initial intense blue color of the solution changes dramatically and its concentration is reduced by reducing the intensity of bands characteristic of the azo dye, as shown in Figure 1 where the time evolution of the spectra collected UV-vis for the solution with $2440 \mathrm{ppm}$ of $\mathrm{H}_{2} \mathrm{O}_{2}$. The reduction occurs in all bands not observed the appearance of new compounds in the visible range, whereby the intermediates are similarly degraded to $\mathrm{CO}_{2}$ and $\mathrm{H}_{2} \mathrm{O}$. The final aspect of the solutions after Fenton and photo Fenton processes is also reflected in Figure 1.

The degradation of the solution by the Fento/photo Fenton process depends on the different parameters of the project, which will be analyzed bellow.

\subsection{Effect of $\mathrm{H}_{2} \mathrm{O}_{2}$ Content}

The effect of $\mathrm{H}_{2} \mathrm{O}_{2}$ content of azo degradation Black B is analyzed by preparing three solutions with $268 \mathrm{ppm}$ of $\mathrm{Fe}(\mathrm{II})$ loaded in an acid medium, to which different contents of $\mathrm{H}_{2} \mathrm{O}_{2}$ are added, so that the final concentration solutions in either 2440, 4800 and $7200 \mathrm{ppm}$. The experiments were performed under 2-lamp radiation. The addition of a higher content of $\mathrm{H}_{2} \mathrm{O}_{2}$ leads to accelerating the speed of decolorization of the solution due to increased hydroxyl radical, as it is shown in Figure 2, although the increase is not excessive considering the large concentration of $\mathrm{H}_{2} \mathrm{O}_{2}$ used.

Analysis of total organic carbon values in the azo dye solutions after the oxidation process, collected in Table 1, indicated that addition of $\mathrm{H}_{2} \mathrm{O}_{2}$ does not entail a significant decrease of the values, so that it was considered a concentration of $2440 \mathrm{ppm}$ of $\mathrm{H}_{2} \mathrm{O}_{2}$ as optimal for later analysis.

\subsection{Effect of Catalyst Content}

For analysis of the effect of the content of catalyst in the degradation of azo solutions with various concentrations of catalyst so that the content of Fe(II) in the solution is 67, 138 and 268 ppm are prepared. All solutions are acidified and $\mathrm{H}_{2} \mathrm{O}_{2}$ is added so that its concentration in the final solution is $2440 \mathrm{ppm}$. The tests were performed under UV light. Initially, the increased concentration of $\mathrm{Fe}(\mathrm{II})$ slightly accelerates the decomposition of $\mathrm{H}_{2} \mathrm{O}_{2}$ into the solution more rapidly generate highly oxidative $\mathrm{OH}$ radicals, as it is shown in Figure 3.

However, from a concentration of Fe(II) in solution of $134 \mathrm{ppm}$, increasing the content of catalyst represents a considerable reduction of the rate of reduction of color, due to the reduced capacity of absorption of light in the solution. The large amount of zeolite prevents the UV radiation to penetrate into the solution, causing the slower and less effective as it can be derived from the values of TOC after testing (Table 2). The results indicate that a concentration of $134 \mathrm{ppm}$ of $\mathrm{Fe}(\mathrm{II})$ corresponds to the optimal both discoloration and reduction of TOC. 
Table 1. TOC values of solutions after the photoFenton process in heterogeneous phase with several $\mathrm{H}_{2} \mathrm{O}_{2}$ concentrations.

\begin{tabular}{ccc}
\hline$\left[\mathrm{H}_{2} \mathrm{O}_{2}\right]$ & TOC $(\mathrm{ppm})$ & TOC reduction (\%) \\
\hline 2440 & 86 & 62.6 \\
4800 & 94 & 59.1 \\
7200 & 62 & 73.0 \\
\hline
\end{tabular}

Table 2. TOC values of solutions after the photoFenton process in heterogeneous phase with several iron concentrations.

\begin{tabular}{ccc}
\hline$\left[\mathrm{Fe}^{2+}\right]$ & TOC $(\mathrm{ppm})$ & TOC reduction (\%) \\
\hline 67 & 72 & 68.2 \\
134 & 46 & 81.3 \\
268 & 86 & 62.6 \\
\hline
\end{tabular}

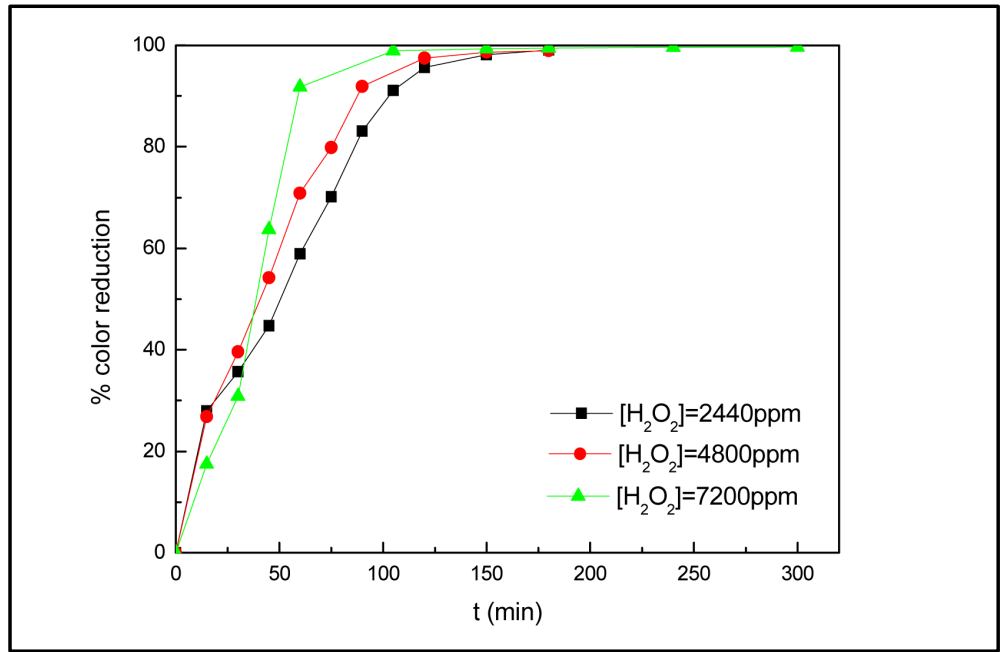

Figure 2. Evolution of the UV-vis absorption spectra of the solution during the process.

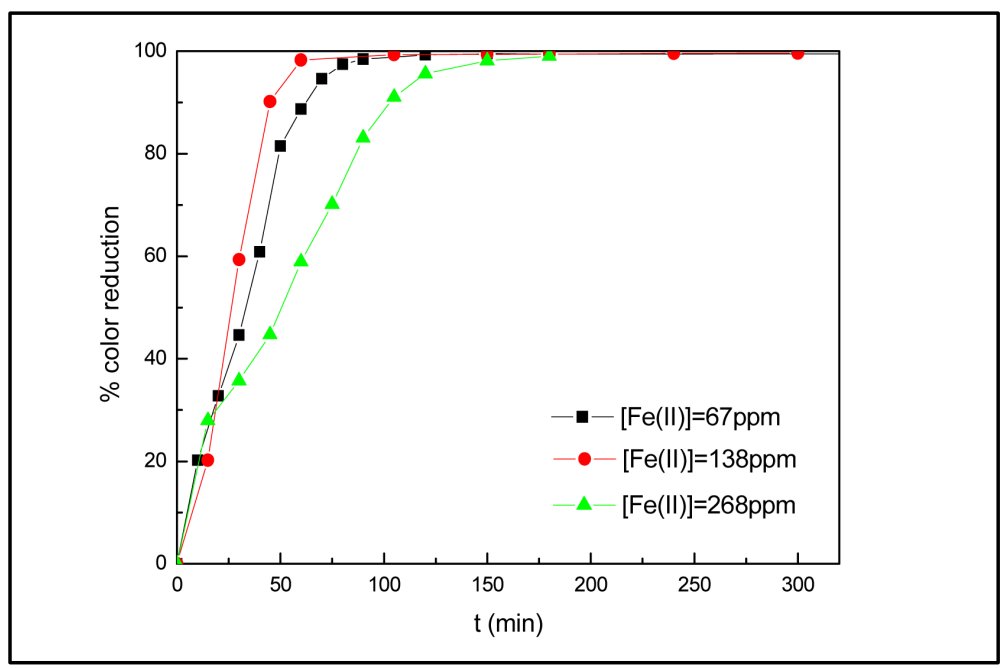

Figure 3. Color removal rate for the photoFenton process in heterogeneous phase with several iron concentrations. 


\subsection{Effect of $\mathrm{pH}$}

In the next step of the study, the effect of initial operating $\mathrm{pH}$ value on the process effectiveness was investigated. Fenton process in its unmodified form is efficient in $\mathrm{pH}$ range 2 - 4. However, heterogeneous Fenton type processes could be effectively operated at milder $\mathrm{pH}$ conditions. In this study, different $\mathrm{pHs}$ have been studied

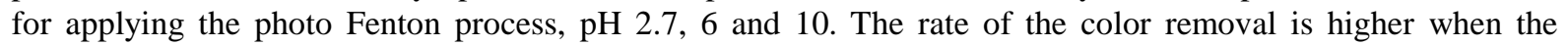
process takes place at acid conditions, as it is shown in Figure 4. Hydrogen peroxide and ferrous ions are more stable when $\mathrm{pH}$ is lower than 3.5. As a result, a better redox system and better mineralization efficiency can be established. On the contrary, ferrous ions are unstable when a $\mathrm{pH}$ value of the system is higher than 4.0, and they would easily form ferric ions which have a tendency to produce ferric hydroxo complexes. The complexes would further form $\left[\mathrm{Fe}(\mathrm{OH})_{4}\right]^{-}$when the $\mathrm{pH}$ is higher than 9.0. Besides, hydrogen peroxide is also unstable in basic solution and may decompose to give oxygen and water and lose its oxidation ability [7]. Interestingly the initial $\mathrm{pH}$ of the solutions increased to lower values. This could be a result of the generation of intermediate acid compounds as a consequence of the degradation of the azo dye. The change in the $\mathrm{pH}$ seemed to increase the color removal rate after 150 minutes of starting the process. However, after finishing the process both samples continued with a blue color, so the degradation of the azo dye was stopped at an early stage. This fact explained the high TOC values of the solutions after the photo Fenton process during $12 \mathrm{~h}$ (Table 3).

It is important to highlight that the quantification of the iron in solution after the heterogeneous process during the optimization steps, in accordance with ISO6332, ensured that the iron is not leached form the support and the oxidation process took place in the heterogeneous phase.

\subsection{Heterogeneous vs Homogeneous Process}

Once the optimization of the photo Fenton process in heterogeneous phase has been done $\left(\left[\mathrm{H}_{2} \mathrm{O}_{2}\right]=2440 \mathrm{ppm}\right.$, $[\mathrm{Fe}(\mathrm{II})]=134 \mathrm{ppm} \mathrm{y} \mathrm{pH} \mathrm{=} \mathrm{2.7),} \mathrm{the} \mathrm{results} \mathrm{obtained} \mathrm{in} \mathrm{heterogeneous} \mathrm{elimination} \mathrm{processes} \mathrm{regarding} \mathrm{TOC} \mathrm{and}$ color are compared to those obtained in homogeneous phase. The rate of decomposition of the azo dye in both phases is collected in Figure 5 for two photo Fenton processes. The rate in the heterogeneous phase is lower than that observed in the homogeneous phase, which may be due to reduced accessibility between the $\mathrm{Fe}(\mathrm{II})$ and $\mathrm{H}_{2} \mathrm{O}_{2}$ as the Fe is occluded in the zeolite channels acting as a support. The presence of solid particles could also provide negative influence on the solution transparency and radiation flux [7]. However, in both cases a complete decolorization is achieved after 90 minutes of reaction, reaching similar TOC values after 8 hours of UV exposure in both types of processes, as it is shown in Table 4. These results indicated that heterogeneous process can be an alternative to conventional homogeneous processes as similar TOC removal degrees are obtained in reasonable time.

\subsection{Reuse of the Catalyst}

In order to check if the catalyst can be reused in the same process, the same catalyst has been used in three consecutive tests, maintaining a similar azo dye solution concentration and process conditions. Between the different tests only a simple water cleaning step was carried out. The study was performed for the Fenton and photoFenton processes. The color removal of the solutions after all processes and the similar TOC reduction achieved after all the processes, shown in Table 5, indicate that it is possible to reuse the catalyst three consecutive cycles without affecting it efficiency in both Fenton and photo Fenton processes.

\subsection{Effect of the Intensity of the Radiation}

Another important parameter to consider is the effect of the intensity of the UV radiation in the efficiency of heterogeneous Fenton type process using Y catalyst. The influence of UV light was investigated within the pH 2.7. For the analysis, the process is performed under photo Fenton radiation from different number of lamps: 2 and 4 lamps. Moreover, the use of solar radiation as an energy source is discussed, which makes the most economical and environmentally friendly process. The degradation rate of the azo dye seems not influenced by the number of lamps. The intensity of the incident radiation from 2 lamps on the solution appears to be sufficient for the bleaching of the dye.

However, the results are different when solar radiation is used as an energy source in the oxidation processes. To analyze the possibility of using solar radiation, a assay is performed in heterogeneous phase under the fol- 


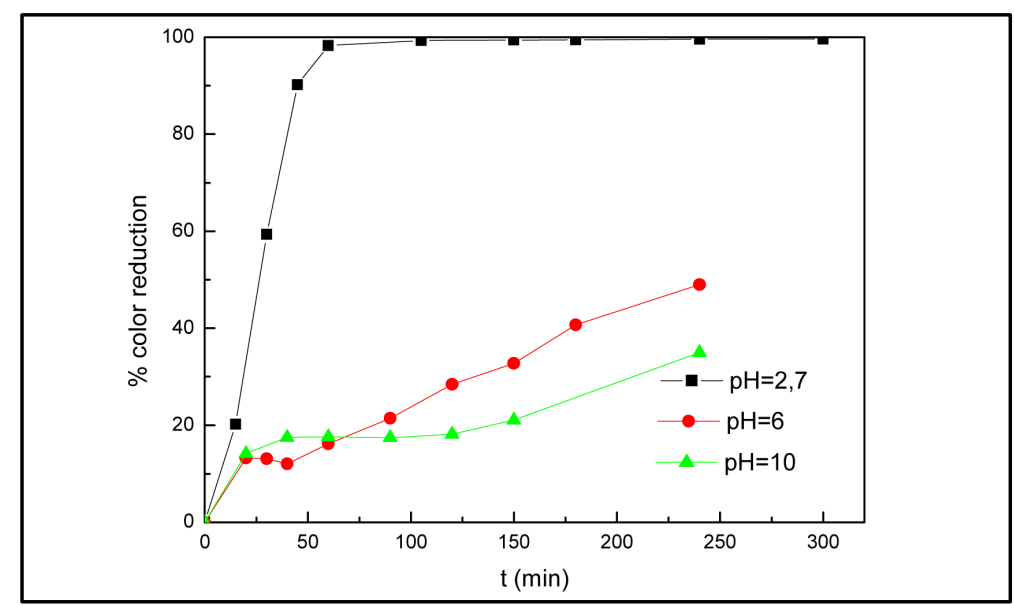

Figure 4. Color removal rate for the photoFenton process in heterogeneous phase with different $\mathrm{pHs}$.

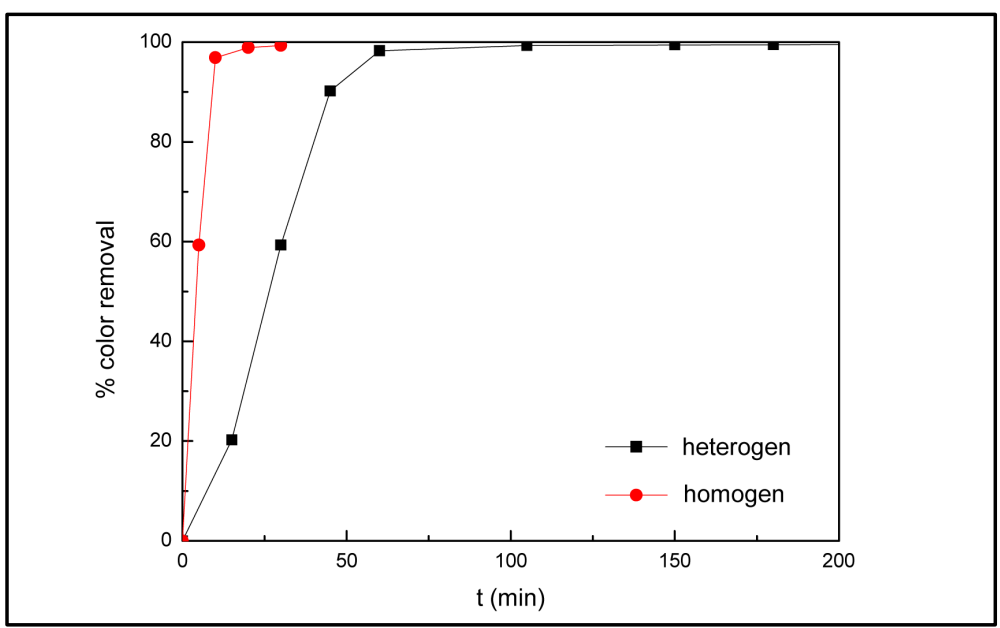

Figure 5. Color removal rate for the photo Fenton process in heterogeneous and homogeneous phases.

Table 3. TOC values of solutions after the photo Fenton process in heterogeneous phase with different pHs.

\begin{tabular}{ccc}
\hline $\mathrm{pH}$ & TOC (ppm) & TOC reduction (\%) \\
\hline 2.7 & 46 & 81.3 \\
6.0 & 155 & 32.6 \\
10.0 & 183 & 20.4 \\
\hline
\end{tabular}

Table 4. TOC values of solutions after the photoFenton process in heterogeneous phase with different pHs.

\begin{tabular}{ccc}
\hline phase & TOC $(\mathrm{ppm})$ & TOC reduction (\%) \\
\hline heterogeneous & 46 & 81.3 \\
homogeneous & 40.5 & 82.4 \\
\hline
\end{tabular}

lowing conditions: $\left[\mathrm{H}_{2} \mathrm{O}_{2}\right]=2440$ ppm, $[\mathrm{Fe}(\mathrm{II})]=268 \mathrm{ppm}$ and $\mathrm{pH}=2.7$, in a parabolic concentrator type solar cooker (Figure 6). By proper orientation of the parabolic concentrator in the direction of the sun, the concave mirrors of the same incident rays concentrated in one point that in this case the solution is placed. Parallel to the 
Table 5. TOC values of solutions after the Fenton and photo Fenton processes in heterogeneous phase.

\begin{tabular}{cccccccc}
\hline \multirow{2}{*}{ Phase } & \multicolumn{2}{c}{ Initial value } & \multicolumn{2}{c}{$1^{\text {st }}$ cycle } & \multicolumn{2}{c}{$2^{\text {nd }}$ cycle } & \multicolumn{2}{c}{$3^{\text {rd }}$ cycle } \\
\cline { 2 - 8 } & TOC (ppm) & TOC (ppm) & TOC reduction (\%) & TOC (ppm) & TOC reduction (\%) & TOC (ppm) & TOC reduction (\%) \\
\hline \multirow{2}{*}{ heterogeneous } & 230 & 109 & 52.6 & 116 & 49.6 & 125 & 45.6 \\
homogeneous & 230 & 71 & 69.1 & 61 & 73.5 & 84 & 63.5 \\
\hline
\end{tabular}

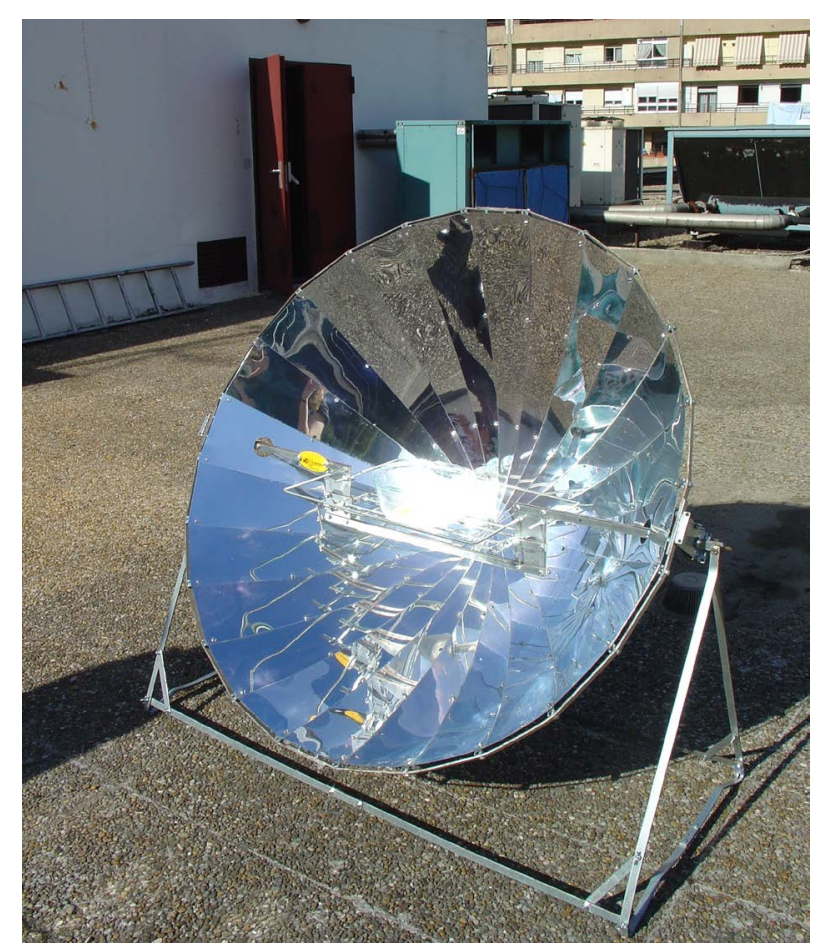

Figure 6. Parabolic concentrator type solar cooker.

concentration of solar radiation, a significant increase in temperature at this point is achieved. After a short time of 45 minutes the complete color removal is achieved, arriving after 2 hours at a value TOC removal similar to that achieved using UV radiation sources. The higher rate observed is increased due on the one hand to the increase in temperature of the resulting azo dye solution due to the concentration of the radiation and on the other hand to the solar radiation that covers a broader range of ultraviolet radiation spectrum than the lamps. The solar radiation that reaches the earth is between 315 - $380 \mathrm{~nm}$ [10] [18] [19]. UVA with wavelength of $365 \mathrm{~nm}$, which is the region of solar light accounts for $98.7 \%$ of the ultraviolet radiation that reaches the Earth's surface.

\section{Conclusion}

In this study, the applicability of Fe-exchanged zeolite of Y-type as a heterogeneous catalyst in Fenton type processes for the degradation of organic model pollutant based on Black B azo dye in water matrix was investigated. It was demonstrated that $\mathrm{H}_{2} \mathrm{O}_{2}$ and catalyst dosage, initial $\mathrm{pH}$, and UV irradiation highly affect the overall process efficiency, i.e. decolorization and mineralization. By optimizing the amount of reactants and process conditions, a complete decolorization of the effluent and a reduction greater than $80 \%$ in the total organic carbon content is achieved. Furthermore, optimization of the catalyst and $\mathrm{H}_{2} \mathrm{O}_{2}$ content involves minimizing the amount of reagents and so the cost of the process. The quantification of iron in solution after the process ensures that the iron is not leached and that the oxidation process occurs heterogeneously. The leaching of iron catalyst from zeolite support is not significative resulting in lower concentration of iron in the bulk after the treatment. The use of solar radiation as a source of energy for operating the process accelerates the decomposition of azo dye, making the process economical and environmentally sustainable. Furthermore, the catalyst support can be 
reused in successive cycles without significant loss of effectiveness. Thus, these processes are presented as viable alternative for use in the decontamination of wastewater from the textile industry.

\section{Acknowledgements}

The authors want to acknowledge the SUDOE and ERDF funding through the project CarbonInspired 2.0 (Grant Agreement SOE4/P1/E793), European Commission funding through the project Setnanometro (EU-FP7-project number 604577) and Basque Government for funding through the project Actimat (Etortek 2013-14).

\section{References}

[1] Bolong, N., Ismail, A.F., Salim, M.R. and Matsuura T. (2009) A Review of the Effects of Emerging Contaminants in Wastewater and Options for Their Removal. Desalination, 239, 229-246. http://dx.doi.org/10.1016/j.desal.2008.03.020

[2] Emami, F., Tehrani-Bagha, A.R., Gharanjig, K. and Menger, F.M. (2010) Kinetic Study of the Factors Controlling Fenton-Promoted Destruction of a Non-Biodegradable Dye. Desalination, 257, 124-128. ttp://dx.doi.org/10.1016/j.desal.2010.02.035

[3] Gogate, P.R. and Pandit, A.B. (2004) A Review of Imperative Technologies for Wastewater Treatment I: Oxidation Technologies at Ambient Conditions. Advances in Environmental Research, 8, 501-551. http://dx.doi.org/10.1016/S1093-0191(03)00032-7

[4] Neyens, E. and Baeyens, J. (2003) A Review of Classic Fenton’s Peroxidation as an Advanced Oxidation Technique. Journal of Hazardous Materials, 98, 33-50. http://dx.doi.org/10.1016/S1093-0191(03)00032-7

[5] Pignatello, J., Oliveros, E. and MacKay, A. (2006) Advanced Oxidation Processes for Organic Contaminant Destruction Based on the Fenton Reaction and Related Chemistry. Critical Reviews in Environmental Science and Technology, 36, 1-84. http://dx.doi.org/10.1080/10643380500326564

[6] Parra, S., Henao, L., Mielczarski, E., Mielczarski, J., Albers, P. and Suvorova, E. (2004) Synthesis, Testing, and Characterization of a Novel Nafion Membrane with Superior Performance in Photo Assisted Immobilized Fenton Catalysis. Langmuir, 20, 5621-5629. http://dx.doi.org/10.1021/la049768d

[7] Aleksić M., Kušić H., Koprivanac N., Leszczynska D. and Božić A.L. (2010) Heterogeneous Fenton Type Processes for the Degradation of Organic Dye Pollutant in Water-The Application of Zeolite Assisted AOPs. Desalination, 257, 22-29. http://dx.doi.org/10.1016/j.desal.2010.03.016

[8] Gonzalez-Olmos, R., Holzer, F., Kopinke, F.D. and Georgi, A. (2011) Indications of the Reactive Species in a Heterogeneous Fenton-Like Reaction Using Fe-Containing Zeolites. Applied Catalysis A: General, 398, 44-53. http://dx.doi.org/10.1016/j.apcata.2011.03.005

[9] Gonzalez-Olmos, R., Martin, M.J., Georgi, A., Kopinke, F.D., Oller, I. and Malato, S. (2012) Fe-Zeolites as Heterogeneous Catalysts in Solar Fenton-Like Reactions at Neutral pH. Applied Catalysis B: Environmental, 125, 51-58. http://dx.doi.org/10.1016/j.apcatb.2012.05.022

[10] Tekbas, M., CengizYatmaz, H. and Bektas, N. (2008) Heterogeneous Photo-Fenton Oxidation of Reactive Azo Dye Solutions Using Iron Exchanged Zeolite as a Catalyst. Microporous and Mesoporous Materials, 115, 594-602. http://dx.doi.org/10.1016/j.micromeso.2008.03.001

[11] Pirkanniemi, K. and Sillanpää, M. (2002) Heterogeneous Water Phase Catalysis as an Environmental Application: A Review. Chemosphere, 48, 1047-1060. http://dx.doi.org/10.1016/S0045-6535(02)00168-6

[12] Soon, A.N. and Hameed, B.H. (2013) Degradation of Acid Blue 29 in Visible Light Radiation Using Iron Modified Mesoporous Silica as Heterogeneous Photo-Fenton Catalyst. Applied Catalysis A: General, 450, 96-105. http://dx.doi.org/10.1016/j.apcata.2012.10.025

[13] Ramirez, J.H., Vicente, M.A. and Madeira, L.M. (2010) Heterogeneous Photo-Fenton Oxidation with Pillared Clay-Based Catalysts for Wastewater Treatment: Review. Applied Catalysis B: Environmental, 98, 10-26. http://dx.doi.org/10.1016/j.apcatb.2010.05.004

[14] Martínez, F., Pariente, M.I., Ángel, J., Botas, J.A., Melero, J.A. and Rubalcaba, A. (2012) Influence of Preoxidizing Treatments on the Preparation of Iron-Containing Activated Carbons for Catalytic Wet Peroxide Oxidation of Phenol. Journal of Chemical Technology and Biotechnology, 87, 880-886. http://dx.doi.org/10.1002/jctb.2744

[15] Santos, A., Yustos, P., Rodríguez, S., Garcia-Ochoa, F. and de Gracia, M. (2007) Decolorization of Textile Dyes by Wet Oxidation Using Activated Carbon as Catalyst. Industrial \& Engineering Chemistry Research, 46, 2423-2427. http://dx.doi.org/10.1021/ie0614576

[16] Pinheiro, H.M., Touraud, E. and Thomas, O. (2004) Aromatic Amines from Azo Dye Reduction: Status Review with Emphasis on Direct UV Spectrophotometric Detection in Textile Industry Wastewaters. Dyes and Pigments, 61, 
121-139. http://dx.doi.org/10.1016/j.dyepig.2003.10.009

[17] Janus, M. and Morawski, A.W. (2007) New Method of Improving Photocatalytic Activity of Commercial Degussa P25 for Azo Dyes Decomposition. Applied Catalysis B: Environmental, 75, 118-123. http://dx.doi.org/10.1016/j.apcatb.2007.04.003

[18] Yao, Y.Y., Wang, L., Sun, L.J., Zhu, S., Huang, Z.F., Mao, Y.J., Lu, W.Y. and Chen, W.X. (2013) Efficient Removal of Dyes Using Heterogeneous Fenton Catalysts Based on Activated Carbon Fibers with Enhanced Activity. Chemical Engineering Science, 101, 424-431. http://dx.doi.org/10.1016/j.ces.2013.06.009

[19] Chacón, J.M., Leal, M.T., Sánchez, M. and Bandala, E.R. (2006) Solar Photocatalytic Degradation of Azo-Dyes by Photo-Fenton Process. Dyes and Pigments, 69, 144-150. http://dx.doi.org/10.1016/j.dyepig.2005.01.020

[20] Belver, C., Bañares-Muñoz, M.A. and Vicente, M.A. (2004) Fe-Saponite Pillared and Impregnated Catalysts: I. Preparation and Characterisation. Applied Catalysis B, 50, 101-112. http://dx.doi.org/10.1016/j.apcatb.2004.01.010

[21] Chen, J. and Zhu, L. (2007) Heterogeneous UV-Fenton Catalytic Degradation of Dye Stuff in Water with Hydroxyl-Fe Pillared Bentonite. Catalysis Today, 126, 463-470. http://dx.doi.org/10.1016/j.cattod.2007.06.022

[22] Dalrymple, O.K., Stefanakos, E., Trotz, M.A. and Goswami, D.Y. (2010) A Review of the Mechanisms and Modeling of Photocatalytic Disinfection. Applied Catalysis B, 98, 27-38. http://dx.doi.org/10.1016/j.apcatb.2010.05.001

[23] Daud, N.K. and Hameed, B.H. (2011) Acid Red 1 Dye Decolorization by Heterogeneous Fenton-Like Reaction Using Fe/Kaolin Catalyst. Desalination, 269, 291-293. http://dx.doi.org/10.1016/j.desal.2010.11.016

[24] Liu, T., You, H. and Chen, Q.W. (2009) Heterogeneous Photo-Fenton Degradation of Polyacrylamide in Aqueous Solution over $\mathrm{Fe}(\mathrm{III})-\mathrm{SiO}_{2}$ Catalyst. Journal of Hazardous Materials, 162, 860-865. http://dx.doi.org/10.1016/j.jhazmat.2008.05.110

[25] Muthuvel, I. and Swaminathan, M. (2007) Photoassisted Fenton Mineralization of Acid Violet 7 by Heterogeneous $\mathrm{Fe}(\mathrm{III})-\mathrm{Al}_{2} \mathrm{O}_{3}$ Catalyst. Catalysis Communications, 8, 981-986. http://dx.doi.org/10.1016/j.catcom.2006.10.015

[26] Flanigen, E.M. (2001) Zeolites and Molecular Sieves: An Historical Perspective. In: Bekkum, H.V., Flanigen, E.M., Jacobs, P.A. and Jansen, J.C., Eds., Studies in Surface Science and Catalysis, Elsevier, Amsterdam, 11-35.

[27] McCusker, L.B. and Baerlocher, C. (2001) Zeolite Structures. In: Bekkum, H.V., Flanigen, E.M., Jacobs, P.A. and Jansen, J.C., Eds., Studies in Surface Science and Catalysis, Elsevier, Amsterdam, 37-67.

[28] Maesen, T. (2007) The Zeolite Scene-An Overview. In: Cejka, J., Bekkum, H.V., Corma, A. and Ferdi, S., Eds., Studies in Surface Science and Catalysis, Elsevier, Amsterdam, 1-12. 